\title{
Prevalence of maxillary canine impaction in skeletal Class III malocclusions compared to Class I malocclusions
}

\author{
Gabriele Di Carlo, Matteo Saccucci, Valeria Luzzi, Gaetano Ierardo, Iole Vozza, Gian-Luca Sfasciotti, Antonella \\ Polimeni
}

Department of Oral and Maxillo-Facial Sciences, Sapienza University of Rome, Viale Regina Elena 287a, 00161 Rome, Italy

Correspondence:

University of Rome "Sapienza"

Via Caserta 6, Roma, Italy

gabriele.dicarlo@uniromal.it

Received: 05/12/2018

Accepted: 07/01/2019

\begin{abstract}
Di Carlo G, Saccucci M, Luzzi V, Ierardo G, Vozza I, Sfasciotti GL, Polimeni A. Prevalence of maxillary canine impaction in skeletal Class III malocclusions compared to Class I malocclusions. J Clin Exp Dent. 2019;11(3):e264-8.

http://www.medicinaoral.com/odo/volumenes/v1li3/jcedv11i3p264.pdf
\end{abstract}

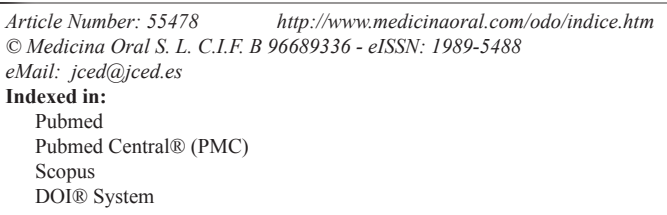

\begin{abstract}
Background: The aim of the present investigation was to evaluate if an orthodontic population of Class III malocclusion patients shows a different prevalence of maxillary canine impaction than Class I subjects.

Material and Methods: Fifty-eight subjects were retrospectively selected and assigned to the Class I group ( $\mathrm{n}=$ 32 ) or the Class III group ( $n=26)$, depending on the ANB and WITS values. Lateral cephalograms were used to collect angular and linear measurements that described the skeletal and dental maxillary features of the subjects, while orthopantomography was used to assess the impaction or the correct eruption of the maxillary canines. An independent samples T-test or a Mann-Whitney U-test was used to compare the cephalometric values between the two groups, while a chi-squared test was used to evaluate the distribution of maxillary canine impaction between the two groups.

Results: No statistically significant difference was found for the cephalometric variables, and the frequency of canine impaction showed no difference between the Class III and Class I subjects.

Conclusions: Patients with skeletal Class III malocclusions did not show a different prevalence of canine impaction; therefore, such skeletal features cannot be used as a diagnostic aid for assessment of the risk of maxillary canine impaction.
\end{abstract}

Key words: Skeletal Class III, Angle Class III, maxillary canine impaction, tooth impaction.

\section{Introduction}

The impaction of maxillary canines is the most frequent eruption pathology after that of mandibular and maxillary third molars, and it is found in almost $2 \%$ of the population (1). The treatment of an impacted canine is a complex multidisciplinary procedure that requires surgical exposure and orthodontic extrusion of the tooth; this requires accurate surgical and biomechanical plan- ning $(2,3)$ and a longer treatment time with respect to a treatment of a similar malocclusion without an impacted tooth (4). Many authors have studied methods to predict the risk of canine impaction, since a correct risk assessment would be of great clinical value. Besides the radiographic criteria developed by Ericson and Kurol (5) and further modified by other authors $(6,7)$ to predict canine impaction from its position in a panoramic 
radiograph, some authors have studied if a patient's dento-skeletal features could be used as a prognostic factor. For example, Mercuri et al. found that the facial skeletal features of patients with a palatally impacted canine are characterized by a horizontal and prognathic growth (8). Larsen et al. observed that the maxillary complex of patients with ectopic canines is enlarged transversally, but smaller in the sagittal and vertical dimensions (9). Similarly, Laurenziello et al. studied the cephalometric characteristics associated with palatally impacted canines and found that facial divergence (SN-GoMe angle) could be used to assess the risk of canine impaction in combination with the $\alpha$-angle (the angle of the long axis of the maxillary canine to the midsagittal plane) and the distance of the canine cusp to the occlusal plane (10). Taken together, these are often the skeletal features of Class III malocclusions $(11,12)$. Basdra et al. observed impacted canines in $9 \%$ of Class III subjects, compared to a frequency of $1.3 \%$ in Class II division 1 subjects (13).

The aim of the present investigation was to study if in an orthodontic population, skeletal Class III subjects exhibit a different prevalence of maxillary canine impaction compared to skeletal Class I subjects. The null hypothesis was that no difference exists in canine impaction prevalence between the two types of skeletal malocclusion.

\section{Material and Methods}

The records of orthodontic patients treated at the XXXXXX from January 2008 to June 2018 were screened for the following inclusion criteria:

- Pre-pubertal age at treatment start;

- Class III malocclusion defined as an ANB angle $<0^{\circ}$ or a WITS appraisal <-3 $\mathrm{mm}$;

- Class I malocclusion defined as an ANB angle comprised between $0^{\circ}$ and $4^{\circ}$, or a WITS appraisal comprised between $-3 \mathrm{~mm}$ and $+1 \mathrm{~mm}$.

The lateral cephalograms of the selected subjects were collected and anonymised with a numerical code. This retrospective study was conducted according to the Declaration of Helsinki, and written informed consent to participate was obtained from all patients. Tracings were performed by a single well-trained operator, and the following measurements were collected:

- ANB, the angle between the skeletal A-point, nasion, and the skeletal B-point;

- WITS, the distance between the perpendicular projections of the skeletal A-point and the skeletal B-point over the occlusal plane;

- Fh-NA, the angle between the Frankfurt plane and the nasion-skeletal A-point plane;

- Fh-PP, the angle between the Frankfurt plane and the palatal plane (anterior nasal spine [ANS] to posterior nasal spine $[\mathrm{PNS}])$;
- ANS-PNS, the length of the palatal plane, i.e. the distance between the ANS and the PNS;

- U1-Fh, the angle between the Frankfurt plane and the long axis of the upper central incisor.

A panoramic radiograph and intraoral photographs were used to assess the normal eruption or the impaction of the maxillary canines. Depending on the ANB and/or WITS value, the subjects were assigned to the Class I group or the Class III group.

Error of the method

To evaluate the error of the method for cephalometric variables, the tracings of 20 randomly selected subjects were repeated after one week by the same operator. An intra-class correlation (ICC) coefficient was calculated between the two sets of measurements to evaluate the intra-operator reliability.

Statistical analysis

An independent samples T-test was used to compare the subjects' age between the Class I and Class III groups, while a $\chi$-square test was used to evaluate the gender distribution between the two groups. A Shapiro-Wilk normality test was used to evaluate the type of data distribution for all the cephalometric variables. An independent samples T-test or a Mann-Whitney U-test, depending on data distribution, was used to compare all the cephalometric variables between the Class I and Class III groups. A $\chi$-square test was used to test the distribution of erupted and impacted maxillary canines between the two groups. The first type error was set as 0.05 for all the statistical tests.

\section{Results}

From the 200 records screened, those of 58 subjects fulfilled the inclusion criteria and were selected for further analysis. According to the ANB and WITS values, 32 subjects were assigned to the Class I group and 26 were assigned to the Class III group. The two groups showed a similar gender and age distribution; therefore, they were comparable, and no significant effect from these two variables would have been observed (Table 1).

Regarding the error of the method, the calculated ICC coefficient was excellent $(>0.85)$ for all the variables, revealing good intra-observer reliability of the measurements.

Descriptive statistics are reported in Table 2. No significant differences were detected between the two groups for Fh-NA, Fh-PP, ANS-PNS, and U1-Fh. The two groups showed a significant difference regarding ANB and WITS values $(P<0.001)$, confirming that the sample was correctly sorted and that a highly different skeletal pattern was present between the groups (Table 2). No difference in the distribution of canine impaction was present between the two groups (Table 3); therefore, the null hypothesis was accepted. 
Table 1: Demographic composition of the two groups.

\begin{tabular}{|l|c|c|c|c|c|}
\hline & \multicolumn{2}{|c|}{ Gender } & \multicolumn{3}{c|}{ Age } \\
\hline & Male & Female & Pearson $\chi$ & Mean \pm SD & T-test $\neq$ \\
\hline Class I group & 16 & 16 & & $10.3 \pm 0.5$ & \\
\hline & & & 0.559 & & 0.969 \\
\hline Class III group & 11 & 15 & & $10.4 \pm 0.5$ & \\
\hline
\end{tabular}

${ }^{t} P$-value from the $\chi$-square test for gender distribution between the two groups; ${ }^{\neq} P$-value for on independent samples T-test for age difference between the two groups; *statistically significant for $P<0.05$.

Table 2: Descriptive statistics and comparison between groups for cephalometric variables.

\begin{tabular}{|c|c|c|c|c|c|c|c|}
\hline \multicolumn{4}{|c|}{+} & \multicolumn{4}{|c|}{ Comparison } \\
\hline & $\begin{array}{c}\text { Class I Group } \\
(\mathrm{n}=\mathbf{3 2})\end{array}$ & $\begin{array}{c}\text { Class III } \\
\text { Group }(n=26)\end{array}$ & $\begin{array}{c}\text { Mean } \\
\text { difference }\end{array}$ & SE & $\boldsymbol{P}$ & $\begin{array}{l}\text { 95\% C.I. } \\
\text { Lower } \\
\text { bound }\end{array}$ & $\begin{array}{l}\text { 95\% C.I. } \\
\text { Upper } \\
\text { bound }\end{array}$ \\
\hline $\operatorname{ANB}\left({ }^{\circ}\right)$ & $2.3 \pm 0.2$ & $0.2 \pm 0.4$ & $121.5+* *$ & - & $<0.001$ & - & - \\
\hline Wits (mm) & $-0.9 \pm 0.2$ & $-4.4 \pm 0.3$ & $40.4 \uparrow * *$ & - & $<0.001$ & - & - \\
\hline Fh-NA $\left({ }^{\circ}\right)$ & $90.9 \pm 0.5$ & $89.4 \pm 0.6$ & $1.56 \ddagger$ & 0.8 & 0.050 & -0.01 & 3.12 \\
\hline Fh-PP $\left({ }^{\circ}\right)$ & $-1.6 \pm 0.6$ & $-0.6 \pm 0.6$ & $-0.95+$ & 0.9 & 0.279 & -2.68 & 0.79 \\
\hline ANS-PNS (mm) & $46.2 \pm 0.7$ & $45.6 \pm 0.6$ & $0.66 t$ & 1.0 & 0.521 & -1.38 & 2.7 \\
\hline $\mathrm{U1-Fh}\left({ }^{\circ}\right)$ & $115.3 \pm 1.2$ & $116.8 \pm 1.7$ & $364.0 \%$ & - & 0.416 & - & - \\
\hline
\end{tabular}

$U$-statistics from Mann-Whitney; ${ }^{\ddagger}$ Mean difference from independent samples T-test; * statistically significant for $P<0.05$; ${ }^{* *}$ statistically significant for $P<0.01$.

Table 3: Crosstabulation and $\chi$ square test for frequency of canine impaction between the two groups.

\begin{tabular}{|l|c|c|c|c|c|c|}
\hline & \multicolumn{3}{|c|}{ Frequencies } & \multicolumn{3}{c|}{$\chi$ square test } \\
\hline & Erupted & Impacted & Total & Perason $\chi$ & df & $P$ \\
\hline Class I group & 11 & 21 & 32 & & & \\
\hline Class III group & 12 & 14 & 26 & 0.832 & 1 & 0.362 \\
\hline Total & 23 & 35 & 58 & & & \\
\hline
\end{tabular}

\section{Discussion}

Predicting the risk of maxillary canine impaction is of great clinical importance, due to the complexity of the treatment of this eruption anomaly: the forced eruption of an impacted canine requires careful biomechanical planning(14) and the use of an orthodontic force magnitude in a physiologic range (15-17) to reduce the risks of root resorption and loss of vitality of the impacted tooth. In addition, a proper anchorage is needed, sometimes involving the use of a miniscrew $(18,19)$, which, on the other hand, represents an additional surgical procedure with its own risks and clinical assessment, requiring also the availability of a sufficient space in a convenient location (20-22). If the risk of maxillary canine impaction is recognized at an early age, an attempt can be made to try to change the eruptive path of the canine; this involves the extraction of the deciduous canine $(23,24)$ and rapid maxillary expansion $(25,26)$, possibly with a device anchored onto the deciduous molars to reduce the side effects on permanent teeth (27-30).

Many authors have tried to study the dento-skeletal features that could predict an increased risk of maxillary canine impaction. Mercuri et al. observed that patients with impacted canines are characterized by a horizontal and prognathic growth, but they concluded that palatally displaced canines and buccally displaced canines are not associated with altered skeletal features (8). Basdra et al., on the other hand, found that canine impaction was associated with Class II division 2 malocclusions in $33.5 \%$ of cases (31) and in $9 \%$ of Class III subjects (13). 
Sacerdoti and Baccetti found a prevalence of canine impaction in hypodivergent patients three times higher than in normal subjects, confirming an association with vertical craniofacial features (32). In addition, Larsen et $a l$. found that patients with impacted canines had a significantly transversally enlarged maxilla, but sagittally and vertically smaller than subjects without impaction, suggesting the need for a three-dimensional evaluation of space for cases with ectopic canines (9).

Some authors have suggested that the association between some skeletal malocclusions and certain tooth anomalies could be due to genetic factors, rather than environmental factors (i.e., a shorter maxilla that makes it more difficult for the canine to erupt) (33). Basdra et al. reported that Class II division 2 malocclusion was associated with genetic-dependent tooth anomalies like agenesis of upper lateral incisors and peg-shaped incisors, in addition to impacted canines (31). Other authors have observed a correlation between maxillary retrognathia and maxillary canine-first premolar transposition (34), a dental anomaly that has been demonstrated to share a common genetic origin with palatally displaced canines (35).

Overall, the existing literature does not provide clear evidence about a possible association between craniofacial features and maxillary canine impaction. The results of the present study confirm that a Class III skeletal pattern cannot be used as a prognostic factor for the risk of development of maxillary canine impaction.

\section{Conclusions}

No association between Class III skeletal features and maxillary canine impaction was found, confirming that such skeletal characteristics cannot be used as a diagnostic and prognostic aid in determining the risk of maxillary canine impaction.

\section{References}

1. Ericson S, Kurol J. Early treatment of palatally erupting maxillary canines by extraction of the primary canines. Eur J Orthod. 1988;10:283-95.

2. Becker A, Chaushu S. Success rate and duration of orthodontic treatment for adult patients with palatally impacted maxillary canines. Am J Orthod Dentofac Orthop. 2003;124:509-14.

3. Bishara SE. Impacted maxillary canines: A review. Am J Orthod Dentofac Orthop. 1992;101:159-71.

4. Stewart JA, Heo G, Glover KE, Williamson PC, Lam EWM, Major PW. Factors that relate to treatment duration for patients with palatally impacted maxillary canines. Am J Orthod Dentofac Orthop. 2001;119:216-25.

5. Ericson S, Kurol J. Radiographic examination of ectopically erupting maxillary canines. Am J Orthod Dentofac Orthop. 1987;91:483-92.

6. Baccetti T, Crescini A, Nieri M, Rotundo R, Pini Prato GP. Orthodontic treatment of impacted maxillary canines: an appraisal of prognostic factors. Prog Orthod. 2007;8:6-15.

7. Stivaros N, Mandall NA. Radiographic factors affecting the management of impacted upper permanent canines. J Orthod. 2000;27:169-73. 8. Mercuri E, Cassetta M, Cavallini C, Vicari D, Leonardi R, Barbato E. Skeletal features in patient affected by maxillary canine impaction. Med Oral Patol Oral Cir Bucal. 2013;18:e597-602.
9. Larsen H, Sorensen H, Artmann L, Christensen I, Kjaer I. Sagittal, vertical and transversal dimensions of the maxillary complex in patients with ectopic maxillary canines. Orthod Craniofac Res. 2010;13:34-9.

10. Laurenziello M, Montaruli G, Gallo C, Tepedino M, Guida L, Perillo L, et al. Determinants of maxillary canine impaction: Retrospective clinical and radiographic study. J Clin Exp Dent. 2017;9:e1304-9.

11. Ellis E, McNamara JA. Components of adult Class III malocclusion. J Oral Maxillofac Surg. 1984;42:295-305.

12. Wolfe SM, Araujo E, Behrents RG, Buschang PH. Craniofacial growth of Class III subjects six to sixteen years of age. Angle Orthod. 2011;81:211-6.

13. Basdra EK, Kiokpasoglou MN, Komposch G. Congenital tooth anomalies and malocclusions: A genetic link? Eur J Orthod. 2001;23:145-51.

14. Fleming PS, Sharma PK, DiBiase AT. How to...mechanically erupt a palatal canine. J Orthod. 2010;37:262-71.

15. Tepedino M, Chimenti C, Masedu F, Iancu Potrubacz M. Predictable method to deliver physiologic force for extrusion of palatally impacted maxillary canines. Am J Orthod Dentofac Orthop. 2018;153:195-203.

16. Iancu Potrubacz M, Chimenti C, Marchione L, Tepedino M. Retrospective evaluation of treatment time and efficiency of a predictable cantilever system for orthodontic extrusion of impacted maxillary canines. Am J Orthod Dentofac Orthop. 2018;154:55-64.

17. Tepedino M, Iancu-Potrubacz M, Grippaudo C, Chimenti C, Laganà $\mathrm{G}$. Does muscular activity related to vertical facial divergence influence the time needed for orthodontic extrusion of palatally impacted maxillary canines?: A retrospective study. J Clin Exp Dent. 2018;10:e869-75.

18. Baumgaertel S, Razavi MR, Hans MG. Mini-implant anchorage for the orthodontic practitioner. Am J Orthod Dentofac Orthop. 2008;133:621-7.

19. Tepedino M, Masedu F, Chimenti C. Comparative evaluation of insertion torque and mechanical stability for self-tapping and self-drilling orthodontic miniscrews: an in vitro study. Head Face Med. 2017;13:1-7.

20. AlSamak S, Gkantidis N, Bitsanis E, Christou P. Assessment of potential orthodontic mini-implant insertion sites based on anatomical hard tissue parameters: a systematic review. Int J Oral Maxillofac Implants. 2012;27:875-87.

21. Baumgaertel S. Cortical bone thickness and bone depth of the posterior palatal alveolar process for mini-implant insertion in adults. Am J Orthod Dentofac Orthop. 2011;140:806-11.

22. Tepedino M, Cattaneo PM, Masedu F, Chimenti C. Average interradicular sites for miniscrew insertion: should dental crowding be considered? Dent Press J Orthod. 2017;22:90-7.

23. Naoumova J, Kurol J, Kjellberg H. A systematic review of the interceptive treatment of palatally displaced maxillary canines. Eur $\mathrm{J}$ Orthod. 2011;33:143-9.

24. Naoumova J, Kurol J, Kjellberg H. Extraction of the deciduous canine as an interceptive treatment in children with palatal displaced canines - part I: Shall we extract the deciduous canine or not? Eur J Orthod. 2015;37:209-18.

25. Baccetti T, Mucedero M, Leonardi M, Cozza P. Interceptive treatment of palatal impaction of maxillary canines with rapid maxillary expansion: a randomized clinical trial. Am J Orthod Dentofac Orthop. 2009;136:657-61.

26. Sigler LM, Baccetti T, McNamara JA. Effect of rapid maxillary expansion and transpalatal arch treatment associated with deciduous canine extraction on the eruption of palatally displaced canines: A 2-center prospective study. Am J Orthod Dentofac Orthop. 2011;139:e235-44. 27. Cozzani M, Guiducci A, Mirenghi S, Mutinelli S, Siciliani G. Arch width changes with a rapid maxillary expansion appliance anchored to the primary teeth. Angle Orthod. 2007;77:296-302.

28. Monaco A, Tepedino M, Sabetti L, Petrucci A, Sgolastra F. An adolescent treated with rapid maxillary expansion presenting with strabismus: A case report. J Med Case Rep. 2013;7:222.

29. Tepedino M, Iancu-Potrubacz M, Ciavarella D, Masedu F, Mar- 
chione L, Chimenti C. Expansion of permanent first molars with rapid maxillary expansion appliance anchored on primary second molars. $\mathrm{J}$ Clin Exp Dent. 2018;10:e241-7.

30. Di Palma E, Tepedino M, Chimenti C, Tartaglia GM, Sforza C. Longitudinal effects of rapid maxillary expansion on masticatory muscles activity. J Clin Exp Dent. 2017;9:e635-40.

31. Basdra EK, Kiokpasoglou M, Stellzig A. The Class II division 2 craniofacial type is associated with numerous congenital tooth anomalies. Eur J Orthod. 2000;22:529-35.

32. Sacerdoti R, Baccetti T. Dentoskeletal features associated with unilateral or bilateral palatal displacement of maxillary canines. Angle Orthod. 2004;74:725-32.

33. Dermaut LR, Goeffers KR, De Smit AA. Prevalence of tooth agenesis correlated with jaw relationship and dental crowding. Am J Orthod Dentofacial Orthop. 1986;90:204-10.

34. Danielsen JC, Karimian K, Ciarlantini R, Melsen B, Kjær I. Unilateral and bilateral dental transpositions in the maxilla: dental and skeletal findings in 63 individuals. Eur Arch Paediatr Dent. 2015;16:467-76.

35. Scerri ES, McDonald F, Camilleri S. Comparison of the dental anomalies found in maxillary canine-first premolar transposition cases with those in palatally displaced canine cases. Eur J Orthod. 2016;38:79-84.

\section{Conflict of Interest}

The authors declare that they have no conflict of interest. 